Mar. Drugs 2010, 8, 2702-2720; doi:10.3390/md8102702

Review

\title{
Marine Antitumor Drugs: Status, Shortfalls and Strategies
}

\section{Ira Bhatnagar ${ }^{1}$ and Se-Kwon Kim ${ }^{1,2, *}$}

1 Department of Chemistry, Pukyong National University, Busan 608-737, Korea; E-Mail: ibhatnagar@gmail.com

2 Marine Bioprocess Research Center, Pukyong National University, Busan 608-737, Korea

* Author to whom correspondence should be addressed; E-Mail: sknkim@pknu.ac.kr; Tel: +82-51-629-7097, Fax: +82-51-629-7099.

Received: 31 August 2010; in revised form: 17 September 2010 / Accepted: 13 October 2010 / Published: 15 October 2010

\begin{abstract}
Cancer is considered as one of the deadliest diseases in the medical field. Apart from the preventive therapies, it is important to find a curative measure which holds no loopholes and acts accurately and precisely to curb cancer. Over the past few decades, there have been advances in this field and there are many antitumor compounds available on the market, which are of natural as well as synthetic origin. Marine chemotherapy is well recognized nowadays and profound development has been achieved by researchers to deal with different molecular pathways of tumors. However, the marine environment has been less explored for the production of safe and novel antitumor compounds. The reason is a number of shortfalls in this field. Though ample reviews cover the importance and applications of various anticancerous compounds from marine natural products, in the present review, we have tried to bring the current status of antitumor research based on marine inhibitors of cancer signaling pathways. In addition, focus has been placed on the shortfalls and probable strategies in the arena of marine antitumor drug discovery.
\end{abstract}

Keywords: marine antitumor compounds; cancer signaling pathways; shortfalls in cancer research; clinical status of antitumor drugs

\section{Introduction}

Cancer has posed a great challenge to the fields of medicine and immunology. Finding novel and efficient compounds of natural origin has been a major point of concern for research in the 
pharmaceutical sciences. Nature harbors a vast variety of flora and fauna including microbial inhabitants and lithosphere, atmosphere and hydrosphere cumulatively provide an excellent source of chemically diverse compounds with great therapeutic potential. Drugs derived from natural products have a giant impact on the antitumor drug discovery regime of the present day [1]. This importance of natural products in the field of therapeutics may be attributed to their high affinity to the target, little loss of entropy when they bind to a protein and their bioavailability. Moreover, natural compounds are quite flexible in conformational acquisition in aqueous and lipophilic environments [2].

The oceanic environment has been a vast source of such natural compounds covering a wide range of bioactivity such as photoprotective [3], antihelmintic, antibacterial, anticoagulant, antifungal, anti-inflammatory, antimalarial, antiprotozoal, antituberculosis, antiviral and other miscellaneous mechanisms of action [4]. For the past two decades, marine pharmaceutics has been a developing field in the antitumor drug development arena. Marine organisms including sponges $[5,6]$, sponge-microbe symbiotic association [7], gorgonian [8], actinomycetes [9], and soft coral [10] have been widely explored for potential anticancer agents.

Despite an array of antitumor compounds that have been produced from the marine environment, a vast majority of oceanic habitat is underexplored due to various problems faced by marine biotechnologists and pharmacists. First, the marine natural products are large in molecule size and complex in structure with multiple chiral centers. Second, lack of technological innovations and financial support coupled with environmental considerations pose hindrances to marine antitumor drug research. Some speedy expansions in molecular biology, bioengineering, genomics, proteomics and metabolomics have aided the discovery of natural products and their implication in antitumor drug development.

This review showcases recent developments in the field of marine antitumor research with emphasis on the signal transduction pathways of oncogenesis, clinical status of the marine derived antitumor compounds and discusses the potential challenges and probable strategies to combat the gap between marine compound isolation and successful antitumor drug development. It is an attempt to focus the attention of the scientific community including biologists and chemists on an integrative approach towards antitumor drug development from marine sources

Figure 1. Chemical structures of some marine derived antitumor compounds. The corresponding references have been superscripted after the compound name [11-25].

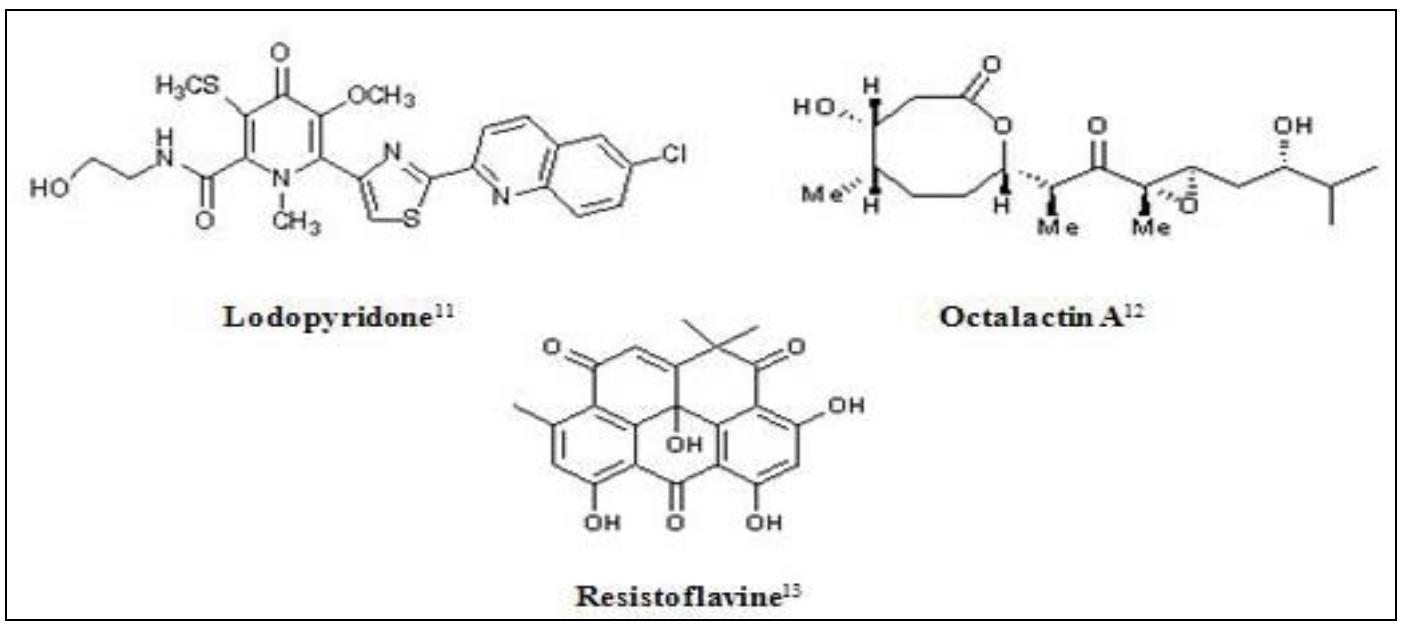


Figure 1. Cont.

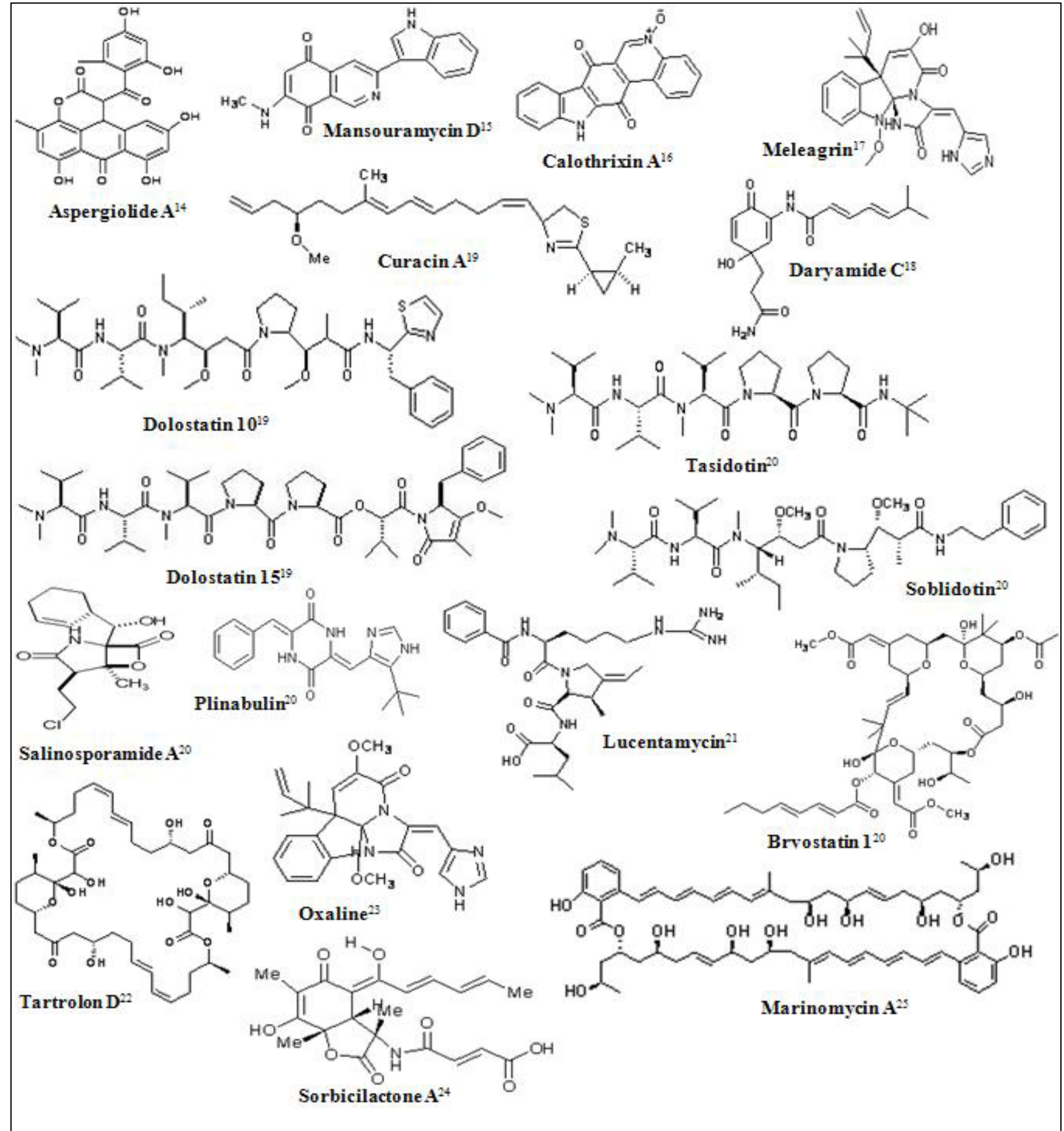

\section{Marine Drugs against Major Players in Cancer}

Carcinogenesis is a complex process controlled by various signal transduction pathways linked to processes such as inflammation, cell differentiation and survival, and metastasis. Most of the players of these pathways are interrelated and irregularities in their crosstalk result in impairment of cellular functions leading to tumor generation and progression. Few such players have been targeted for cancer therapy and some inhibitors from marine sources have been designed and studied to counteract tumor progression and curb carcinogenesis. Some such studies are reviewed in this section. 


\subsection{MMP Inhibitors}

Matrix metalloproteinases (MMPs), zinc dependant endopeptidases that degrade the extracellular matrix (ECM) [26], have been extensively focused on due to their evident role in carcinogenesis and cellular invasion by catabolizing the extracellular matrix [27]. Apart from playing a major role in invasion, angiogenesis, and metastasis during tumor progression, MMPs are also important for cancer cell transformation, growth, apoptosis, signal transduction and immune regulation [28,29]. Marine sources have been extensively explored for potential MMP inhibitors [30]. Kim et al. (2006) reported the inhibitory effect of marine derived chitooligosaccharides (COS) on the activation and expression of matrix metalloproteinase-2 (MMP-2) in primary human dermal fibroblasts (HDFs). They found that medium molecular weight $\operatorname{COS}(3-5 \mathrm{kDa})$ exhibited highest inhibitory effects by reducing the gene expression and transcriptional activity of MMP-2 [31].

Further, Quang et al. (2006) investigated the effect of low molecular weight COS (1-3 kDa) on the activity and expression of MMP-9 in HT1080 cells and confirmed the inhibition by gelatin zymography [32]. To understand the molecular basis of the MMP-9 inhibitory effect of COS, Rajapakse et al. evaluated carboxylated chitooligosaccharides (CCOS) on human fibrosarcoma cell line. A clear dose-dependent inhibition on MMP-9 mediated gelatinolytic activities were observed in HT1080 cells following the treatment with CCOS in zymography experiments. Transfection studies carried out with MMP-9 and AP-1 reporter constructs suggested that the observed reduction in MMP-9 expression was due to down-regulation of MMP-9 transcription mediated via inhibition of AP-1. However, in the presence of CCOS, NF- $\mathrm{KB}$ and TIMP-1 expression levels remained constant [33].

Wang et al. (2008) isolated the sulfated S. maindroni ink polysaccharide (SIP-SII) from cuttlefish Sepiella maindroni and examined the effects of SIP-SII on the expression of matrix metalloproteinases MMP-2 and MMP-9 as well as tumor cell invasion and migration. SIP-SII $(0.8-500 \mathrm{mg} / \mathrm{mL})$ significantly decreased the expression of MMP-2 activity in human ovarian carcinoma cells SKOV3. No significant decrease of MMP-9 activity was detected in the cell line after SIP-SII treatment [34]. MMP inhibitory effects of phlorotannins from marine brown algae Ecklonia cava (EC) have also been studied. Fluorometric assay revealed that EC extract could specifically inhibit both MMP-2 and MMP-9 activities significantly $(\mathrm{P}<0.001)$ at a concentration of $10 \mu \mathrm{g} / \mathrm{mL}$ in human dermal fibroblasts and HT1080 cells. In addition, EC extract did not exert any cytotoxic effect even at $100 \mu \mathrm{g} / \mathrm{mL}$, proposing its potential use as a safe MMP inhibitor [35].

\subsection{HIF Inhibitors}

To design effective drugs against cancer, it is mandatory to understand the underlying tumor physiology and the changes occurring in the tumor microenvironment [36]. It has been observed that tumor progression is associated with not only increased microvascular density but also intratumoral hypoxia [37]. Further, loss of HIF-1 activity has been shown to have immense negative effects on tumor growth, vascularization and energy metabolism in xenograft assays [38,39]. Thus a number of HIF inhibitors have been designed with the aim of finding new direction to tumor therapy. Laurenditerpenol, isolated from bioassay-guided fractionation of the lipid extract of the red alga Laurencia intricata Lamouroux (Rhodomelaceae), yielded the first marine natural product that 
inhibited HIF-1 activation [40]. It was shown to inhibit HIF-1 activation by blocking hypoxia-induced HIF-1 $\alpha$ protein accumulation and suppressed mitochondrial oxygen consumption at ETC complex I at an $\mathrm{IC}_{50}$ value of $0.8 \mu \mathrm{M}$.

In search of potent and selective small-molecule HIF-1 inhibitors, Liu et al. (2007) observed 81\% inhibition of hypoxia-induced HIF-1 activation by the crude extract of the sponge Dendrilla nigra (Aplysillidae) at a concentration of $5 \mu \mathrm{g} / \mathrm{mL}$. The study was carried out using T47D human breast carcinoma cell-based reporter assay and the bioassay-guided chromatographic separation yielded four new lamellarin-like phenolic pyrroles that bear structural features similar to Lamellarin O [41]. A year later, the same group identified and characterized a structurally unique inhibitor of HIF-1 activation, Furospongolide (IC50 $2.9 \mu \mathrm{M}$, T47D breast tumor cells) from a marine sponge Lendenfeldia sp. One new cytotoxic scalarane sesterterpene was also reported from the same extract. They found that Furospongolide blocked the induction of the downstream HIF-1 target secreted vascular endothelial growth factor (VEGF) and suppressed HIF-1 activation by inhibiting the hypoxic induction of HIF-1 $\alpha$ protein. It was found to suppress tumor cell respiration via the blockade of NADH-ubiquinone oxidoreductase (complex I)-mediated mitochondrial electron transfer [42].

Lipid extract of the crinoid Comantheria rotula (Comasteridae) yielded seven Benzo[g]chromen-4one and Benzo[h]chromen-4-one pigments. The crinoid's pigments significantly inhibited both hypoxia-induced $\left(\mathrm{IC}_{50}\right.$ values 1.7-7.3 $\mu \mathrm{M}$ ) and iron chelator-induced HIF-1-dependent luciferase reporter activity $\left(\mathrm{IC}_{50}\right.$ values 0.6 to $3.0 \mu \mathrm{M}$ ) in $\mathrm{T} 47 \mathrm{D}$ cells. Four of these pigments were also reported to significantly suppress HIF-1 activation in PC-3 prostate tumor cells [43]. A number of other structurally diverse marine natural product-derived HIF inhibitors including Manassantin B [44], 7-hydroxyneolamellarin A [41] have also been discovered in past some years. An extensive review published last year covers most of the information on HIF inhibitors of natural origin including compounds from marine algae and marine organisms [45].

\subsection{Nuclear Factor- $\kappa B$ Inhibitors}

Nuclear factor- $\kappa \mathrm{B}(\mathrm{NF}-\kappa \mathrm{B})$ is a ubiquitous transcription factor, a dimer of proteins of the Rel family

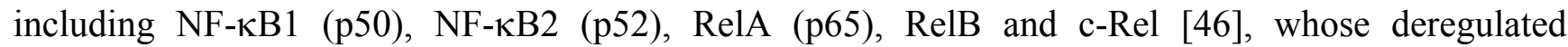
expression may lead to cancer (Figure 2). NF- $\kappa B$ is activated by various stimuli, including TNF- $\alpha$ (tumor necrosis factor- $\alpha$ ), interleukin-1 and lipopolysaccharide [47]. Certain fungal metabolites show promising potential as novel anti-cancer agents as they modulate the activity of NF- $\kappa \mathrm{B}$. Folmer et al. (2008) divided NF- $\mathrm{KB}$ inhibitors into four categories: (a) compounds targeting the IKK-dependent degradation of $\mathrm{IkB}$, (b) compounds specifically interfering with the proteolytic activity of the $26 \mathrm{~S}$ proteasome, (c) compounds interfering with the binding of NF- $\kappa \mathrm{B}$ to its DNA binding site, and (d) compounds with unknown mechanisms of action [48]. Marizomib (Salinosporamide A; NPI-0052), a proteasome inhibitor isolated from a marine bacterium Salinispora tropica, has a great potential as an anticancer drug [49]. A study published last year reported three new cyclohexadepsipeptides, Arenamides (A-C) from the fermentation broth of a marine bacterial strain Salinispora arenicola. They

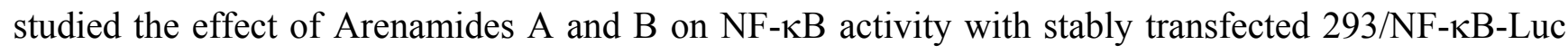
human embryonic kidney cells induced by treatment with tumor necrosis factor (TNF). It was observed 
that Arenamides A and B blocked TNF-induced activation of NF- $\kappa \mathrm{B}$ in a dose- and time-dependent manner [50].

Even marine derived sediments are rich in bioactive substances which may prove to be potential NF- $\kappa B$ inhibitors. Nam and coworkers (2010) have recently isolated Fijiolide A, a potent inhibitor of TNF- $\alpha$-induced NF- $\kappa B$ activation, from a marine-derived bacterium of the genus Nocardiopsis. It was observed to reduce TNF- $\alpha$-induced NF- $\kappa \mathrm{B}$ activation by $70.3 \%$, with an $\mathrm{IC}_{50}$ value of $0.57 \mu \mathrm{M}$. Their data proposes Fijiolide A as a promising lead for more advanced anticancer testing [51]. The biological effects of Heteronemin, a marine sesterterpene isolated from the sponge Hyrtios sp., were studied recently by Schumacher and colleagues on chronic myelogenous leukemia cells. In their observation, heteronemin inhibited both trypsin and chymotrypsin-like proteasome activity at an $\mathrm{IC}_{50}$ value of $0.4 \mu \mathrm{M}$ thereby inhibiting $\mathrm{NF}-\kappa \mathrm{B}$ activation and proving to be detrimental to cancer cells via apoptosis [52].

Figure 2. Role of TNF- $\alpha$ induced NF- $\kappa \mathrm{B}$ in carcinogenesis. During inflammation, TNF- $\alpha$ induced NF- $\kappa$ B acts on proliferating cells thereby causing their malfunction and leading to cancer.

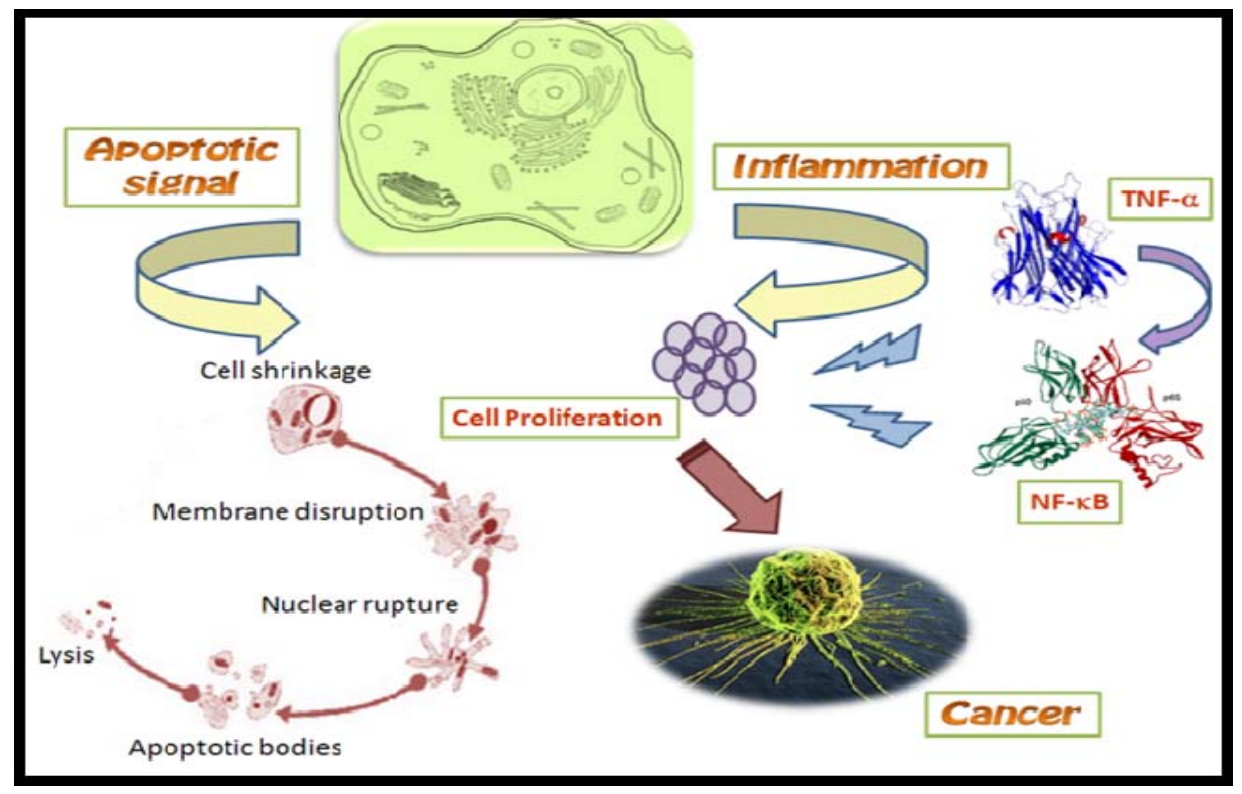

\subsection{Topoisomerase Inhibitors}

Topoisomerases play a major role in maintaining the integrity of the DNA helix during replication, transcription, and chromosome condensation in mitosis [53] and thus are important for cell proliferation. They are now being targeted for anticancer therapy. Over the past three decades, numerous topoisomerase inhibitors have been isolated from various natural sources, in order to find an effective anticancer drug. These agents either prevent the formation of covalent bonds between topoisomerase and DNA or stabilize the intermediate topoisomerase-DNA covalent binary complex thus preventing DNA relegation. They preclude DNA replication and transcription, and thereby lead to the death of cells attempting to undergo these processes (Figure 3). 
Figure 3. Schematic representation of the mode of action of Topoisomerase inhibitors by (A) preventing covalent bond formation or (B) preventing DNA resealing. Here, represents Topoisomerase enzyme and $\bigcirc$ represents Topoisomerase inhibitor.

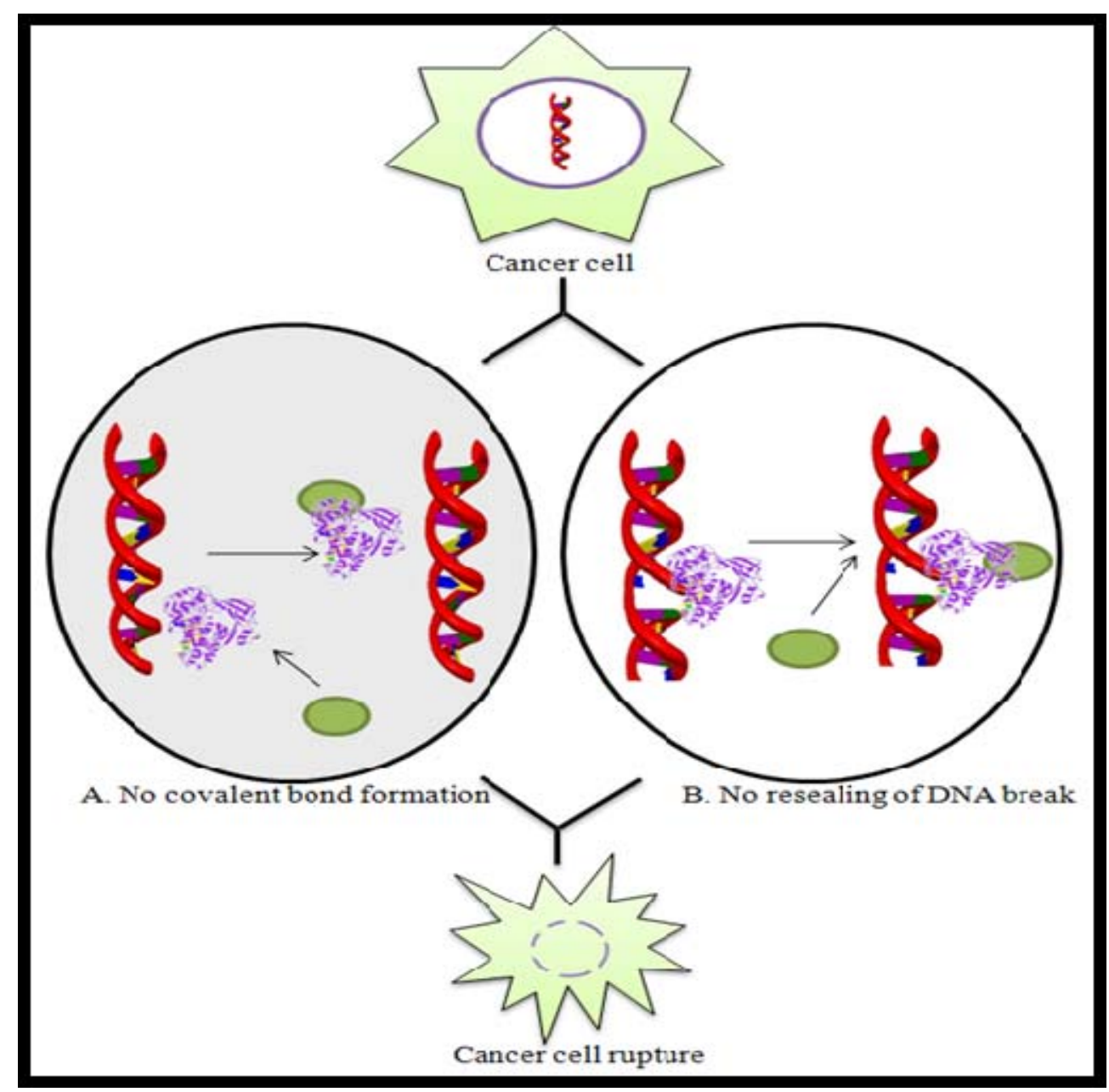

Makaluvamine $\mathrm{A}$ is a pyrroloquinoline, principally isolated from the sponge Zyzzya fuliginosa and is known to have potent anticancer activity via inhibiting topoisomerase II [54]. Ascididemin (ASC) is an aromatic alkaloid isolated from the mediterranean ascidian Cystodytes dellechiajei [55], which has been shown by Dassonneville and coworkers as a strong inducer of apoptosis in HL-60 and P388 leukemia cells. Through relaxation assays using supercoiled DNA, they showed that ASC stimulated double-stranded cleavage of DNA by topoisomerase II, but exerted only a very weak effect on topoisomerase I [56]. Yet another alkaloid, Lamellarin D (LAM-D), initially isolated from a prosobranch mollusc of the genus Lamellaria, has been recently shown to target topoisomerase I. Tardy et.al. (2004) conducted studies at the molecular and cellular levels to determine the mechanism of action of this alkaloid and concluded that LAM-D potently stabilizes topoisomerase I-DNA covalent complexes so as to promote the formation of DNA single strand breaks [57].

\subsection{PKC Inhibitors}

Members of the protein kinase $\mathrm{C}$ (PKC) family of serine/threonine kinases are known to be major players in oncogenesis. One of the isoforms, $\mathrm{PKC} \varepsilon$, has been demonstrated to increase proliferation, 
motility, and invasion of fibroblasts or immortalized epithelial cells. It has been proven in xenograft and transgenic animal models that overexpression of $\mathrm{PKC} \varepsilon$ is tumorigenic, resulting in metastatic disease [58]. The marine environment has provided a very efficient class of PKC inhibitors, known as Bryostatins. These are highly oxygenated marine macrolides with a unique polyacetate backbone. Since their discovery from the marine animal Bugula neritina in 1982 [59], and showing high activity against the murine P388 lymphocytic leukemia, 20 natural Bryostatins are a part of our knowledge today [60]. Their low toxicity and antineoplastic nature makes them promising candidates for cancer chemotherapeutics. Bryostatin-1 is a macrocyclic lactone derived from a marine invertebrate that binds to the regulatory domain of protein kinase C. Short-term exposure to Bryostatin-1 promotes activation of PKC, whereas prolonged exposure promotes significant downregulation of PKC. It has been reported that Bryostatin-1 inhibits proliferation, induces differentiation, and promotes apoptosis in numerous hematological and solid tumor cell lines [61]. It has been proven to be such a promising candidate that it is being evaluated as an antitumor agent against myeloma, acute myeloid leukemia, chronic lymphocytic leukemia (CCL), AIDS-related lymphoma, non-Hodgkin's lymphoma, colorectal, renal, prostate, head and neck, cervix, ovarian, breast, peritoneal, stomach, esophagus, anus and non-small cell lung cancer [60]. Studies are now underway to understand the chemical basis of the biological activity of Bryostatins. Keck et al. (2009) prepared a close structural analogue of Bryostatin-1, which differs from it only by the absence of the $\mathrm{C}$ (30) carbomethoxy group (on the $\mathrm{C}$ (13) enoate of the B-ring), by total synthesis. They further attributed the biological properties of Bryostatin-1 to the substitution in the A-ring [62].

\section{Clinical Status of Marine Derived Antitumor Drugs}

Although the number of natural products is increasing day by day, very few compounds find their way to the market. This may be due to many factors, particularly the cytotoxicity that they show on normal human cell lines, rendering the compound unfit for use as medicinal supplement. Despite the failure rate, some potential compounds have shown promising results as antitumor agents in preclinical trials and many have made it to different phases of clinical trials. Some of them have already been approved as potent anticancer drugs and are already on the market. Cytarabine, Ara-C (Cytosar- $\left.\mathrm{U}^{\circledR}\right)$, a DNA polymerase inhibitor is one such drug developed by Bedford laboratories and Enzon pharmaceuticals, which has been approved for use as an antitumor agent. Trabectedin or Ecteinascidin 743 (Yondelis ${ }^{\circledR}$ ), an alkaloid of tunicate origin, has been approved in European countries to be used for the treatment of soft tissue sarcoma [20]. With an integrated approach of microbiology, screening and natural products chemistry, the marine microbial metabolites are now advancing to be the pharmaceutically important drug candidates. Many compounds of different chemical class and with different mechanisms of action are under clinical trials to prove their potential as antitumor drugs (Table 1). 
Table 1. Clinical status of marine derived antitumor agents, their chemical class and mode of action.

\begin{tabular}{|c|c|c|c|c|c|}
\hline Compound Name & Chemical Class & Organism & Mode of action & Company & Status \\
\hline Cytarabine, Ara-C & Nucleoside & Sponge & DNA Polymerase Inhibitor & Bedford, Enzon & Approved \\
\hline Trabectedin (ET-743) & Alkaloid & Tunicate & Cell cycle arrest & PharmaMar & Approved \\
\hline $\begin{array}{l}\text { Eribulin Mesylate } \\
\text { (E7389) }\end{array}$ & Macrolide & Sponge & Microtubule interfering agent & Eisai Inc. & Phase III \\
\hline & & & vascular disrupting agent & Pharmaceuticals & \\
\hline Squalamine lactate & Aminosteroid & Shark & $\begin{array}{l}\text { Calcium binding protein } \\
\text { antagonist }\end{array}$ & Genaera & Phase II \\
\hline Cemadotin & Peptide & Sea slug & Microtubule interfering agent & Knoll & Phase II \\
\hline Plinabulin (NPI-2358) & Diketopiperazine & Fungus & Vascular disrupting agent & $\begin{array}{l}\text { Nereus } \\
\text { Pharmaceuticals }\end{array}$ & Phase II \\
\hline Plitidepsin & Depsipeptide & Tunicate & Apoptosis inducer & PharmaMar & Phase II \\
\hline Elisidepsin & Depsipeptide & Mollusc & - & PharmaMar & Phase II \\
\hline Zalypsis & Alkaloid & Nudibranch & Cell cycle arrest & PharmaMar & Phase II \\
\hline $\begin{array}{l}\text { Tasidotin, Synthadotin } \\
\text { (ILX-651) }\end{array}$ & Peptide & Bacterium & Microtubule interfering agent & $\begin{array}{l}\text { Genzyme } \\
\text { Corporation }\end{array}$ & Phase II \\
\hline Discodermolide & Polyketide & Sponge & Microtubule interfering agent & Novartis & Phase I \\
\hline HT1286 & Dipeptide & Sponge & Microtubule interfering agent & Wyeth & Phase I \\
\hline LAF389 & $\begin{array}{l}\text { Amino acid } \\
\text { derivative }\end{array}$ & Sponge & $\begin{array}{l}\text { Methionine aminopeptidase } \\
\text { inhibitor }\end{array}$ & Novartis & Phase I \\
\hline Kahalalide F & Cyclic depsipeptide & Sea slug/alga & Lysosomotropic & PharmaMar & Phase I \\
\hline Bryostatin 1 & Polyketide & Bacterium/ Bryozoa & PKC isozyme inhibitor & $\begin{array}{l}\text { National Cancer } \\
\text { Institute }\end{array}$ & Phase I \\
\hline Hemiasterlin (E7974) & Tripeptide & Sponge & Microtubule interfering agent & Eisai Inc. & Phase I \\
\hline $\begin{array}{l}\text { Marizomib, } \\
\text { Salinosporamide A; } \\
\text { NPI-0052) }\end{array}$ & $\begin{array}{l}\text { Beta-lactone-gamma } \\
\text { lactam }\end{array}$ & Bacterium & Proteasome inhibitor & $\begin{array}{l}\text { Nereus } \\
\text { Pharmaceuticals }\end{array}$ & Phase I \\
\hline LY355703, CRYPTO 52 & Cryptophycin & Cyanobacterium & Microtubule interfering agent & - & Preclinical \\
\hline $\begin{array}{l}\text { Depsipeptide (NSC } \\
630176)\end{array}$ & Bicyclic peptide & Cyanobacterium & Histone deacetylase inhibitor & - & Preclinical \\
\hline
\end{tabular}

Eribulin mesylate (E 7389), a macrolide natural product isolated from marine sponges [63] is shown to be a promising microtubule interfering agent leading to cell death by apoptosis [64] and is currently under Phase III clinical trials. Another natural compound under Phase III clinical trials is a peptide Soblidotin (TZT-1027), derived from a marine bacterium [20]. It acts in a dual manner by inhibiting tubulin assembly and disrupting the vasculature of tumor cells, causing them to collapse [65]. Apart from Squalamine lactate, an aminosteroid obtained from shark, and Cemadotin, a peptide obtained from sea slug, few other compounds are under Phase II clinical trials. These include Plitidepsin $\left(\right.$ Aplidin $^{\circledR}$ ), a marine depsipeptide from tunicate Aplidium albicans, which is a potent apoptosis inducer as depicted in both in vitro and in vivo studies [66]. Yet another compound is a diketopiperazine known as Plinabulin (NPI-2358), isolated from a marine alga associated Aspergillus sp CNC-139 [67]. 
This compound also inhibits tubulin assembly and acts as a vasculature disrupting agent that destabilizes the tumor vascular endothelial architecture and leads to cell damage [68].

Bryostatin 1, a polyketide isolated initially from Bryozoa, is now known to be produced by its bacterial symbioant, Candidatus Endobugula sertula [69]. It basically works as a PKC isozyme inhibitor and is currently under Phase I clinical trial under the aegis of the National Cancer Institute (USA) [20]. Another fungal symbioant, Penicillium chrysogenum of the marine sponge Ircinia fasciculata produces an antileukemic agent- Sorbicillactone-A, which has qualified now for human trials, owing to its amazing anticancer properties [70]. Marizomib (Salinosporamide A; NPI-0052) Salinosporamide A, a proteasome inhibitor isolated from a marine bacterium Salinispora tropica [49], is also undergoing Phase I clinical trials under the auspices of Nereus Pharmaceuticals (San Diego, CA). Interesting properties such as a broader and longer lasting proteasome inhibition, efficacy against a wider range of hematologic malignancies and many solid tumor models, less cytotoxicity to normal cells, higher in vivo potency and potential for both oral and intravenous administration makes Salinosporamide A a very promising anticancer agent [71]. Two natural products of cyanobacterial origin (LY355703, CRYPTO52 and Depsipeptide (NSC 630176) are under preclinical trials. Depsipeptide (NSC 630176) is a bicyclic peptide isolated from Chromobacterium violaceum. It is known to decrease mRNA expression of the $c-M Y C$ oncogene thereby causing cell-cycle arrest at G0-G1 [72].

\section{Shortfalls in Marine Antitumor Drug Research}

Although much development has been achieved in the fields of biomedicine and pharmaceutical sciences, still very few natural products have found their way to the market till date. There are ample reasons that may be affecting this shortfall, including; lack of sufficient amount of natural product, difficulties in accessing the source of the samples, problems associated with harvesting of the product, troubles in synthesizing the necessary amounts of the compound, difficulties in isolation and purification procedures, high toxicity of the active compound, ecological considerations, government policies, lack of infrastructure and insufficient capital investment.

For example, studies on the marine HIF inhibitor Laurenditerpenol were hindered by a lack of compound supply [45]. Many species of microorganisms produce specific metabolites at specific phases of their growth. A slight alteration in the culture parameters may lead to changes in the amount and type of metabolite produced thus leading to insufficient supply of the compound. As mentioned earlier in this review, topoisomerase plays a major role in cancer. A new isoform-human topoisomerase III, identified a couple of years ago [73], cleaves single-strand DNA and binds covalently to the 5'-end of the cleaved DNA [74]. Even eight years after its discovery, there are yet no specific inhibitors for topoisomerase III. In addition to this, a recent article in Nature throws light on the dual action of HIF- $\alpha$ in different conditions, which poses a question for its use as a molecular target for cancer therapy [75].

A number of marine microorganisms are difficult to culture and lack of literature on the isolation procedures and standardized culture conditions makes the situation even worse, with less numbers of academics undertaking such studies. For instance, despite the fact that the marine actinomycetes may be a storehouse of novel bioactive molecules, different from terrestrial counterparts, they are an 
underexploited source for the discovery of novel secondary metabolites [76], the main reason being the lack of efforts spent in exploring them. In addition, the fact that the terrestrial actinomycetes produce resistant spores which get transported from land to oceans, where they can remain available but dormant for many years, has made researchers more skeptical for the existence of indigenous populations of marine actinomycetes [77]. Thus, the myth prevails that marine actinomycetes are originally terrestrial. This lack of knowledge prevents uncovering of the vast potential of marine actinomycetes.

A lack of understanding of cancer biomarkers (major players in carcinogenesis and tumor progression) is also a major shortfall in harnessing the marine environment for specific tumor targeting drugs. Despite a vast array of technologies in cancer research with unprecedented depths of analyses, the complexity of cancer proteomics and the underlying altered signaling pathways pose a great challenge for marine antitumor drug research. There is an imperative need for extensive, integrative and collaborative endeavors to explicate proteome alterations in cancer [78]. Moreover, even after knowing the targets and the development of novel marine drugs against the same, fewer and fewer breakthrough ideas find their way out of research institutions and into the hands of experienced clinicians and medical product development teams as the promising research and innovation are not being translated into new treatments. The increasing drug resistant mutations in cancer causing microbial agents, further leads to the lesser number of antitumor drugs in the market.

Certain other issues that pose an obstacle to the marine antitumor drug research include lack of funding and infrastructure resources and experience in the biotechnology firms to perform the extensive late-stage clinical development programs that are needed for regulatory approval of a drug. The reluctance of large pharmaceutical companies to invest in early-stage research raises another financial setback for marine natural product research. It may be because of the lack of surety of novelty and proven market potential; moreover, it even requires a longer period of time for the investments to be actually returned in terms of profit. The huge structural diversity of marine natural compounds makes it difficult for the isolation and purification of these compounds and the development of novel antitumor drugs from these natural sources possesses problems that are not usually met when one deals with synthetic compounds.

Prevailing threats to global marine biodiversity including overfishing, habitat loss, invasive species and pollution, rising water temperatures and ocean acidification are further making marine antitumor drug research more and more difficult.

\section{Strategies to Combat the Pitfalls}

The discovery of modern anticancer drugs aims to search for improved cytotoxic agents in terms of the accuracy, efficacy and target specificity and sensitivity. The vast biodiversity of the marine environment can serve as a rich source of such natural compounds. However, keeping the above mentioned challenges in view, it becomes mandatory to design specific strategies for improvement of their therapeutic potential.

A semisynthetic approach could be one of the alternatives to enhance the yield of lead natural compounds. It can be achieved by modifying the functional groups of existing natural compounds. This would lead to the generation of structural analogues with greater pharmacological activity and 
with fewer side effects. For example, studies on the marine HIF inhibitor Laurenditerpenol were hindered by a lack of compound supply. However, a recently completed total synthesis has resolved the absolute configuration of Laurenditerpenol [79] and together with other synthetic efforts [80] may provide sufficient compound to allow further evaluation. A more integrated approach comprising high-throughput screening methods, computational biology and bioinformatics may be useful in producing compounds that are more efficient than the ones that are prevalent today. Increasing use of genomics and implication of combinatorial biosynthesis can be applied for discovery and modification of natural marine microbial products.

Marine fungi are prolific producers of bioactive compounds including antitumor drugs [81-83]. A more intrinsic insight in the biology and interspecies relationship of marine fungi would help for better understanding of the kind of compounds that may be isolated from them. As per Raghukumar (2008), a more systematic research should be initiated for fungi from deep-sea, hypoxic zones (with low oxygen levels) and hydrothermal vents for enzymes, degradation of xenobiotics and bioremediation applications. He further suggested that genomic and proteomic studies with novel organisms such as Corallochytrium limacisporum as a model of animal fungal allies will hopefully help in basic research on evolutionary biology [84]. Macrofungi has already been a great source of anticancer agents [85]. An evolutionary approach coupled with an ecological perspective can do wonders in the field of marine natural product discovery and a careful approach in this field can lead to increased production of bioactive compounds with high efficiency. Another effective strategy would be molecular modification for example, implication of ribosome engineering to develop mutant strains that overproduce secondary metabolites by screening various drug-resistance mutations. The efficacy of the strain improvement has recently been highlighted in Streptomyces sp. by introducing combinatory drug-resistances [86].

Targeted therapy has been an indispensable approach towards oncogenic signaling pathways. Drug-specific modulation of oncogenic signaling pathways in specific patient subpopulations can predict responsiveness to targeted therapy. Andersen et al. (2010) recently reported a pathway-based phosphoprofiling approach to identify and quantify clinically relevant, drug-specific biomarkers for phosphatidylinositol 3-kinase (PI3K) pathway inhibitors that target AKT, phosphoinositide-dependent kinase 1 (PDK1), and PI3K-mammalian target of rapamycin (mTOR) [87]. Another alternative would be to improvise different targeted cancer proteome projects and initiatives with clearly delineated objectives. Advances in the field of proteomics, genomics and metabolomics are integral to cell metabolism and have great impact on the identification of new antitumor targets. Not only this, there are newer fields of biology, such as pharmacogenomics and pharmacogenetics, which are proving to be very helpful for understanding patient susceptibility to specific pharmacological agents.

As far as the problems associated with HIF are concerned, Semenza (2002) suggested that the combination of an anti-angiogenic agent and an inhibitor of HIF-1 might be particularly efficacious, as the angiogenesis inhibitor would cut off the tumor's blood supply and the HIF-1 inhibitor would prevent the ability of the tumor to adapt to the ensuing hypoxia and thus the efficacy of HIF inhibitor may be greatly enhanced [36]. As suggested by Borkakoti (2004), the use of MMP inhibitors in combination therapy and in early stages of disease onset, could be a novel approach geared towards achieving improved clinical advantage [88]. 


\section{Conclusions}

One of the greatest challenges for the field of medicine and immunology is finding a sure shot cure for cancer. An extensive research regime needs to be started to combat the ability of cancer cells to mutate and become resistant to available drugs. As mentioned above, collaborative scientific approaches with a focus on molecular mechanisms of tumorigenesis need to be initiated. Efforts are required to gain deeper knowledge regarding the various signal transduction pathways linked to cellular processes such as inflammation, cell differentiation and survival, carcinogenesis, and metastasis. Although it is very difficult to predict the final outcome of such a scheme of drug discovery, it can be assured that a focused approach and combined efforts would definitely accelerate the development of new marine antitumor drugs to be discovered with increased efficiency.

\section{Acknowledgements}

This research was supported by Marine Bioprocess Research Center of the Marine Bio 21 center funded by the 'Ministry of Land, Transport and Maritime', Republic of Korea. The authors are thankful to Jayachandran Venkatesan for redrawing the chemical structures in the Figure 1.

\section{References}

1. da Rocha, A.B.; Lopes, R.M.; Schwartsmann, G. Natural products in anticancer therapy. Curr. Opin. Pharmacol. 2001, 1, 364-369.

2. McCullagh, M. Natural product pharmaceuticals-the third generation. Drug Disc. World 2008. Available online: http://www.ddw-online.com/drug_discovery/258437/natural_product_ pharmaceuticals_the_third_generation.html (accessed on 25 August 2009).

3. Pallela, R.; Yoon, N.-Y.; Kim, S.K. Anti-photoaging and photoprotective compounds derived from marine organisms. Mar. Drugs 2010, 8, 1189-1202.

4. Mayer, A.M.; Rodríguez, A.D.; Berlinck, R.G.; Hamann, M.T. Marine pharmacology in 2005-6: Marine compounds with anthelmintic, antibacterial, anticoagulant, antifungal, anti-inflammatory, antimalarial, antiprotozoal, antituberculosis, and antiviral activities; affecting the cardiovascular, immune and nervous systems, and other miscellaneous mechanisms of action. Biochim. Biophys. Acta 2009, 1790, 283-308.

5. Hickford, S.J.; Blunt, J.W.; Munro, M.H. Antitumour polyether macrolides: Four new halichondrins from the New Zealand deep-water marine sponge Lissodendoryx sp. Bioorg. Med. Chem. 2009, 17, 2199-2203.

6. Aoki, S.; Cao, L.; Matsui, K.; Rachmat, R.; Akiyama, S.-i.; Kobayashi, M. Kendarimide A, a novel peptide reversing P-glycoprotein-mediated multidrug resistance in tumor cells, from a marine sponge of Haliclona sp. Tetrahedron 2004, 60, 7053-7059.

7. Thomas, T.R.A.; Kavlekar, D.P.; LokaBharathi, P.A. Marine Drugs from Sponge-Microbe Association-A Review. Mar. Drugs 2010, 8, 1417-1468

8. Rodriguez, A.D.; Martinez, N. Marine antitumor agents: 14-deoxycrassin and pseudoplexaurol, new cembranoid diterpenes from the Caribbean gorgonian Pseudoplexaura porosa. Experientia 1993, 49, 179-181. 
9. Olano, C.; Méndez, C.; Salas, J.A. Antitumor Compounds from Marine Actinomycetes. Mar. Drugs 2009, 7, 210-248.

10. Hassan, H.M.; Khanfar, M.A.; Elnagar, A.Y.; Mohammed, R.; Shaala, L.A.; Youssef, D.T.; Hifnawy, M.S.; El Sayed, K.A. Pachycladins A-E, prostate cancer invasion and migration inhibitory Eunicellin-based diterpenoids from the red sea soft coral Cladiella pachyclados. J. Nat. Prod. 2010, 73, 848-853.

11. Maloney, K.N.; Macmillan, J.B.; Kauffman, C.A.; Jensen, P.R.; Dipasquale, A.G.; Rheingold, A.L.; Fenical, W. Lodopyridone, a structurally unprecedented alkaloid from a marine actinomycete. Org. Lett. 2009, 11, 5422-5424.

12. Tapiolas, D.M.; Roman, M.; Fenical, W.; Stout, T.J.; Clardy, J. Octalactins A and B: cytotoxic eight-membered-ring lactones from a marine bacterium, Streptomyces sp. J. Am. Chem. Soc. 1991, 113, 4682-4683.

13. Gorajana, A.;Venkatesan, M.; Vinjamuri, S.; Kurada, V.V.S.N.B.; Peela, S.; Jangam, P.; Poluri, E.; Zeeck, A. Resistoflavine, cytotoxic compound from a marine actinomycete, Streptomyces chibaensis AUBN1/7. Microbiol. Res. 2007, 162, 322-327.

14. Du, L.; Zhu, T.; Fang, Y.; Liu, H.; Gu, Q.; Zhu, W. Aspergiolide A, a novel anthraquinone derivative with naphtho(1,2,3-de)chromene-2,7-dione skeleton isolated from a marine-derived fungus Aspergillus glaucus. Tetrahedron 2007, 63, 1085-1088.

15. Hawas, U.W.; Shaaban, M.; Shaaban, K.A.; Speitling, M.; Maier, A.; Kelter, G.; Fiebig, H.H.; Meiners, M.; Helmke, E.; Laatsch, H. Mansouramycins A-D, cytotoxic isoquinolinequinones from a marine streptomycete. J. Nat. Prod. 2009, 72, 2120-2124.

16. Rickards, R.W.; Rothschild, J.M.; Willis, A.C.; de Chazal, N.M.; Kirk, J.; Kirk, K.; Saliba, K.J.; Smith, G.D. Calothrixins A and B, novel pentacyclic metabolites from Calothrix cyanobacteria with potent activity against malaria parasites and human cancer cells. Tetrahedron 1999, 55, 13513.

17. Du, L.; Feng, T.; Zhao, B.; Li, D.; Cai, S.; Zhu, T.; Wang, F.; Xiao, X.; Gu, Q. Alkaloids from a deep ocean sediment-derived fungus Penicillium sp. and their antitumor activities. J. Antibiot. 2010, 63, 165-170.

18. Asolkar, R.N.; Jensen, P.R.; Kauffman, C.A.; Fenical, W. Daryamides A-C, Weakly Cytotoxic Polyketides from a Marine-Derived Actinomycete of the Genus Streptomyces Strain CNQ-085. J. Nat. Prod. 2006, 69, 1756-1759.

19. Tan, L.T. Bioactive natural products from marine cyanobacteria for drug discovery. Phytochemistry 2007, 68, 954-979.

20. Mayer, A.M.S.; Glaser, K.B.; Cuevas, C.; Jacobs, R.S.; Kem, W.; Little, R.D.; McIntosh, J.M.; Newman, D.J.; Potts, B.C.; Shuster D.E. The odyssey of marine pharmaceuticals: a current pipeline perspective. Trends Pharmacol. Sci. 2010, 31(6), 255-265.

21. Cho, J.Y.; Williams, P.G.; Kwon, H.C.; Jensen, P.R.; Fenical, W. Lucentamycins A-D, cytotoxic peptides from the marine-derived actinomycete Nocardiopsis lucentensis. J. Nat. Prod. 2007, 70, 1321-1328.

22. Pérez, M.; Crespo, C.; Schleissner, C.; Rodríguez, P.; Zúñiga, P.; Reyes, F. Tartrolon D, a cytotoxic macrodiolide from the marine-derived actinomycete Streptomyces sp. MDG-04-17-069. J. Nat. Prod. 2009, 72, 2192-2194. 
23. Koizumi, Y.; Arai, M.; Tomoda, H.; Omura, S. Oxaline, a fungal alkaloid, arrests the cell cycle in M phase by inhibition of tubulin polymerization. Biochim. Biophys. Acta. 2004, 1693, 47-55.

24. Bringmann, G.; Gulder, T.A.; Lang, G.; Schmitt, S.; Stöhr, R.; Wiese, J.; Nagel, K.; Imhoff, J.F. Large-scale biotechnological production of the antileukemic marine natural product sorbicillactone A. Mar. Drugs 2007, 5, 23-30.

25. Kwon, H.C.; Kauffman, C.A.; Jensen, P.R.; Fenical, W. Marinomycins A-D, AntitumorAntibiotics of a New Structure Class from a Marine Actinomycete of the Recently Discovered Genus "Marinispora". J. Am. Chem. Soc. 2006, 128, 1622-1632.

26. Lee, M.; Murphy, G. Matrix metalloproteinases at a glance. J. Cell Sci. 2004, 117, 4015-4016.

27. Gill, S.; Parks, W. Metalloproteinases and their inhibitors: regulators of wound healing. Int. J. Biochem. Cell Biol. 2008, 40, 1334-1347.

28. Egeblad, M.; Werb, Z. New functions for the matrix metalloproteinase in cancer progression. Nat. Rev. Cancer 2002, 2, 161-174.

29. Overall, C.M.; Lopez-Otin, C. Strategies for MMP inhibition in cancer: innovations for the posttrial era. Nat. Rev. Cancer 2002, 2, 657-672.

30. Chen, Z.; Kim, S.K. Matrix Metalloproteinase Inhibitors (MMPIs) from Marine Natural Products: the Current Situation and Future Prospects. Mar. Drugs 2009, 7, 71-84.

31. Kim, M.M.; Kim, S.K. Chitooligosaccharides inhibit activation and expression of matrix metalloproteinase-2 in human dermal fibroblasts. FEBS Lett. 2006, 580, 2661-2666.

32. Van Ta, Q.; Kim, M.M.; Kim, S.K. Inhibitory effect of chitooligosaccharides on matrix metalloproteinase-9 in human fibrosarcoma cells (HT1080). Mar. Biotechnol. 2006, 8, 593-599.

33. Rajapakse, N.; Kim, M.M.; Mendis, E.; Huang, R.H.; Kim, S.K. Carboxylated chitooligosaccharides (CCOS) inhibit MMP-9 expression in human fibrosarcoma cells via downregulation of AP-1. Biochim. Biophys. Acta 2006, 1760, 1780-1788.

34. Wang, S.B.; Cheng, Y.N.; Wang, F.S.; Sun, L.R.; Liu, C.H.; Chen, G.J.; Li, Y.H.; Ward, S.G.; $\mathrm{Qu}, \mathrm{X} . J$. Inhibition activity of sulfated polysaccharide of Sepiella maindroni ink on matrix metalloproteinase (MMP)-2. Biomed. Pharmacother. 2008, 62, 297-302.

35. Kim, M.M.; van Ta, Q.; Mendis, E.; Rajapakse, N.; Jung, W.K.; Byun, H.G.; Jeon, Y.J.; Kim, S.K. Phlorotannins in Ecklonia cava extract inhibit matrix metalloproteinase activity. Life Sci. 2006, 79, 1436-1443.

36. Semenza, G.L. HIF-1 and tumor progression: pathophysiology and therapeutics. Trends Mol. Med. 2002, 8(Suppl.), S62-S67.

37. Hockel, M.; Vaupel, P. Tumor hypoxia: definitions and current clinical, biologic, and molecular aspects. J. Natl. Cancer Inst. 2001, 93, 266-276.

38. Semenza, G.L. Hypoxia-inducible factor 1: oxygen homeostasis and disease pathophysiology. Trends Mol. Med. 2001, 7, 345-350.

39. Kung, A.L.; Wang, S.; Klco, J.M.; Kaelin, W.G.; Livingston, D.M. Suppression of tumor growth through disruption of hypoxia-inducible transcription. Nat. Med. 2000, 6, 1335-1340.

40. Mohammed, K.A.; Hossain, C.F.; Zhang, L.; Bruick, R.K.; Zhou, Y.D.; Nagle, D.G. Laurenditerpenol, a New Diterpene from the Tropical Marine Alga Laurencia intricata that Potently Inhibits HIF-1 Mediated Hypoxic Signaling in Breast Tumor Cells. J. Nat. Prod. 2004, 67, 2002-2007. 
41. Liu, R.; Liu, Y.; Zhou, Y.D.; Nagle, D.G Molecular-Targeted Antitumor Agents 15: Neolamellarins from the Marine Sponge Dendrilla nigra Inhibit Hypoxia-Inducible Factor-1 (HIF-1) Activation and Secreted Vascular Endothelial Growth Factor (VEGF) Production in Breast Tumor Cells. J. Nat. Prod. 2007, 70, 1741-1745.

42. Liu, Y.; Liu, R.; Mao, S.C.; Morgan, J.B.; Jekabsons, M.B.; Zhou, Y.D.; Nagle, D.G. MolecularTargeted Antitumor Agents. 19. Furospongolide from a Marine Lendenfeldia sp. Sponge Inhibits Hypoxia-Inducible Factor-1 Activation in Breast Tumor Cells. J. Nat. Prod. 2008, 71, 1854-1860.

43. Dai, J.; Liu, Y.; Jia, H.; Zhou, Y.D.; Nagle, D.G. Benzochromenones from the marine crinoid Comantheria rotula inhibit hypoxia-inducible factor-1 (HIF-1) in cell-based reporter assays and differentially suppress the growth of certain tumor cell lines. J. Nat. Prod. 2007, 70, 1462-1466.

44. Hodges, T.W.; Hossain, C.F.; Kim, Y.P.; Zhou, Y.D.; Nagle, D.G. Molecular-Targeted Antitumor Agents: The Saururus cernuus Dineolignans Manassantin B and 4-O-Demethylmanassantin B Are Potent Inhibitors of Hypoxia-Activated HIF-1. J. Nat. Prod. 2004, 67, 767-771.

45. Nagle, D.G.; Zhou, Y.D. Marine natural products as inhibitors of hypoxic signaling in tumors. Phytochem. Rev. 2009, 8, 415-429.

46. Keutgens, A.; Robert, I.; Viatour, P.; Chariot, A. Deregulated NF-kB activity in haemological malignancies. Biochem. Pharmacol. 2006, 72, 1069-1080.

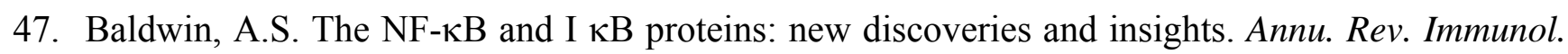
1996, 14, 649-683.

48. Folmer, F.; Jaspars, M.; Dicato, M.; Diederich, M. Marine natural products as targeted modulators of the transcription factor NF-kappa B. Biochem. Pharmacol. 2008, 75, 603-617.

49. Feling, R.H.; Buchanan, G.O.; Mincer, T.J.; Kauffman, C.A.; Jensen, P.J.; Fenical, W. Salinosporamide A: a highly cytotoxic proteasome inhibitor from a novel microbial source, a marine bacterium of the new genus Salinospora. Angew. Chem. 2003, 42, 355-357.

50. Asolkar, R.N.; Freel, K.C.; Jensen, P.R.; Fenical, W.; Kondratyuk, T.P.; Park, E.J.; Pezzuto, J.M. Arenamides A-C, cytotoxic NFkappaB inhibitors from the marine actinomycetes Salinispora arenicola. J. Nat. Prod. 2009, 72, 396-402.

51. Nam, S.J.; Gaudêncio, S.P.; Kauffman, C.A.; Jensen, P.R.; Kondratyuk, T.P.; Marler, L.E.; Pezzuto, J.M.; Fenical, W. Fijiolides A and B, inhibitors of TNF-alpha-induced NFkappaB activation, from a marine-derived sediment bacterium of the genus Nocardiopsis. J. Nat. Prod. 2010, 73, 1080-1086.

52. Schumacher, M.; Cerella, C.; Eifes, S.; Chateauvieux, S.; Morceau, F.; Jaspars, M.; Dicato, M.; Diederich, M. Heteronemin, a spongean sesterterpene, inhibits TNF alpha-induced NF-kappa B activation through proteasome inhibition and induces apoptotic cell death. Biochem. Pharmacol. 2010, 79, 610-622.

53. Champoux, J.J. DNA Topoisomerases: Structure, Function, and Mechanism. Ann. Rev. Biochem. 2001, 70, 369-413.

54. Dias, N.; Vezin, H.; Lansiaux, A.; Bailly, C. Topoisomerase Inhibitors of Marine Origin and Their Potential Use as Anticancer Agents. Top. Curr. Chem. 2005, 253, 89-108. 
55. Bonnard, I.; Bontemps, N.; Lahmy, S.; Banaigs, B.; Combaut, G.; Francisco, C.; Colson, P.; Houssier, C.; Waring, M.J.; Bailly, C. Binding to DNA and cytotoxic evaluation of ascididemin, the major alkaloid from the Mediterranean ascidian Cystodytes dellechiajei. Anticancer Drug Des. 1995, 10, 333-346.

56. Dassonneville, L.; Wattez, N.; Baldeyrou, B.; Mahieu, C.; Lansiaux, A.; Banaigs, B.; Bonnard, I.; Bailly, C. Inhibition of topoisomerase II by the marine alkaloid ascididemin and induction of apoptosis in leukemia cells. Biochem Pharmacol. 2000, 60(4), 527-537.

57. Tardy, C.; Facompré, M.; Laine, W.; Baldeyrou, B.; García-Gravalos, D.; Francesch, A.; Mateo, C.; Pastor, A.; Jiménez, J.A.; Manzanares, I.; Cuevas, C.; Bailly, C. Topoisomerase I-mediated DNA cleavage as a guide to the development of antitumor agents derived from the marine alkaloid lamellarin D: triester derivatives incorporating amino acid residues. Bioorg. Med. Chem. 2004, 12(7), 1697-1712.

58. Gorin, M.A.; Pan, Q. Protein kinase CE: an oncogene and emerging tumor biomarker. Mol. Cancer 2009, 8, 9.

59. Pettit, G.R.; Herald, C.L.; Doubek, D.L.; Herald, D.L.; Arnold, E.; Clardy, J. Isolation and structure of bryostatin 1. J. Am. Chem. Soc. 1982, 104, 6846-6848.

60. Mutter, R.; Wills, M. Chemistry and Clinical Biology of the Bryostatins. Bioorg. Med. Chem. 2000, 8, 1841-1860.

61. Kortmansky, J.; Schwartz, G.K. Bryostatin-1: A novel PKC inhibitor in clinical development. Cancer Invest. 2003, 21, 924-936.

62. Keck, G.E.; Poudel, Y.B.; Welch, D.S.; Kraft, M.B.; Truong, A.P.; Stephens, J.C.; Kedei, N.; Lewin, N.E.; Blumberg, P.M. Substitution on the A-ring confers to bryopyran analogues the unique biological activity characteristic of bryostatins and distinct from that of the phorbol esters. Org. Lett. 2009, 11, 593-596.

63. Jackson, K.L.; Henderson, J.A., Phillips, A.J. The Halichondrins and E7389. Chem. Rev. 2009, 109(7), 3044-3079.

64. Okouneva, T.; Azarenko, O.; Wilson, L.; Littlefield, B.A.; Jordan, M.A. Inhibition of centromere dynamics by eribulin (E7389) during mitotic metaphase. Mol. Cancer Ther. 2008, 7, 2003-2011.

65. Watanabe, J.; Natsume, T.; Kobayashi, M. Comparison of the antivascular and cytotoxic activities of TZT-1027 (Soblidotin) with those of other anticancer agents. Anticancer Drugs 2007, 18, 905-911.

66. Mitsiades, C.S.; Ocio, E.M.; Pandiella, A.; Maiso, P.; Gajate, C.; Garayoa, M.; Vilanova, D.; Montero, J.; Mitsiades, N.; McMullan, C.J.; Munshi, N.C.; Hideshima, T.; Chauhan, D.; Aviles, P.; Otero, G.; Faircloth, G.; Mateos, M.V.; Richardson, P.G.; Mollinedo, F.; San-Miguel, J.F.; Anderson, K.C. Aplidin, a marine organism-derived compound with potent antimyeloma activity in vitro and in vivo. Cancer Res. 2008, 68, 5216-5225.

67. Kanoh, K.; Kohno, S.; Asari, T.; Harada, T.; Katada, J.; Muramatsu, M.; Kawashima, H.; Sekiya, H.; Uno, I. (-)-Phenylahistin: A new mammalian cell cycle inhibitor produced by Aspergillus ustus. Bioorg. Med. Chem. Lett. 1997, 7, 2847-2852.

68. Nicholson, B.; Lloyd, G.K.; Miller, B.R.; Palladino, M.A.; Kiso, Y.; Hayashi, Y.; Neuteboom, S.T. NPI-2358 is a tubulin-depolymerizing agent: in-vitro evidence for activity as a tumor vascular-disrupting agent. Anticanc. Drugs 2006, 17, 25-31. 
69. Davidson, S.K.; Allen, S.W.; Lim, G.E.; Anderson, C.M.; Haygood, M.G. Evidence for the biosynthesis of bryostatins by the bacterial symbiont "Candidatus Endobugula sertula" of the bryozoan Bugula neritina. Appl. Environ. Microbiol. 2001, 67, 4531-4537.

70. Thakur, N.L.; Thakur, A.L. Marine Biotechnology: an overview. Ind. J. Biotechnol. 2006, 5, 263-268.

71. Nereus Pharmaceuticals homepage. Available online: http://www.nereuspharm.com/ overview.shtml (accessed on 02 July 2010).

72. Schwartsmann, G.; Da Rocha, A.B.; Berlinck, R.G.; Jimeno, J. Marine organisms as a source of new anticancer agents. Lancet Oncol. 2001, 2, 221-225.

73. Wang Y.; Lyu, Y.L.; Wang, J.C. Dual localization of human DNA topoisomerase IIIalpha to mitochondria and nucleus. Proc. Natl. Acad. Sci. USA 2002, 99, 12114-12119.

74. Goulaouic, H.; Roulon, T.; Flamand, O.; Grondard, L.; Lavelle, F.; Riou, J.F. Purification and characterization of human DNA topoisomerase III alpha. Nucleic Acids Res. 1999, 27, 2443-2450.

75. Swami, M. Hypoxia: The HIF2 $\alpha$ puzzle. Nat. Rev. Cancer 2010, 10, 603.

76. Lam, K.S. Discovery of novel metabolites from marine actinomycetes. Curr. Opin. Microbiol. 2006, 9, 245-251.

77. Bull, A.T.; Ward, A.C.; Goodfellow. M. Search and discovery strategies for biotechnology: the paradigm shift. Microbiol. Mol. Biol. Rev. 2000, 64, 573-606.

78. Hanash, S.; Taguchi, A. The grand challenge to decipher the cancer proteome. Nat. Rev. Cancer 2010, 10, 652-660.

79. Chittiboyina, A.G.; Kumar, G.M.; Carvalho, P.B.; Liu, Y.; Zhou, Y.D.; Nagle, D.G.; Avery, M.A. Total synthesis and absolute configuration of laurenditerpenol: a HIF-1 activation inhibitor. $J$. Med. Chem. 2007, 50, 6299-6302.

80. Jung, M.E., Im, G.Y.J. Convergent total synthesis of the racemic HIF-1 inhibitor laurenditerpenol. Tetrahedron Lett. 2008, 49, 4962-4964.

81. Bhadury, P.; Mohammad, B.T.; Wright, P.C. The current status of natural products from marine fungi and their potential as anti-infective agents. J. Ind. Microbiol. Biotechnol. 2006, 33, 325-337.

82. Newman, D.J.; Hill, R.T. New drugs from marine microbes: the tide is turning. J. Ind. Microbiol. Biotechnol. 2006, 33, 539-544.

83. Belofsky, G.N.; Jensen, P.R.; Fenical, W. Sansalvamide: A new cytotoxic cyclic depsipeptide produced by a marine fungus of the genus Fusarium. Tetrahedron Lett. 1999, 40, 2913-2916.

84. Raghukumar, C. Marine fungal biotechnology: an ecological perspective. Fungal Divers. 2008, 31, 19-35.

85. Moradali, M.F.; Mostafavi, H.; Ghods, S.; Hedjaroude, G.A. Immunomodulating and anticancer agents in the realm of macromycetes fungi (macrofungi). Int. Immunopharmacol. 2007, 7, 701-724.

86. Xie, S.; Xiao, J.; Xu, J. Advance in microbial ribosome engineering. Wei Sheng Wu Xue Bao. 2009, 49, 981-986. 
87. Andersen, J.N.; Sathyanarayanan, S.; Di Bacco, A.; Chi, A.; Zhang, T.; Chen, A.H.; Dolinski, B.; Kraus, M.; Roberts, B.; Arthur, W.; Klinghoffer, R.A.; Gargano, D.; Li, L.; Feldman, I.; Lynch, B.; Rush, J., Hendrickson, R.C.; Blume-Jensen, P.; Paweletz, C.P. Pathway-based identification of biomarkers for targeted therapeutics: Personalized oncology with PI3K pathway inhibitors. Sci. Transl. Med. 2010, 2, 43ra55.

88. Borkakoti, N. Matrix metalloprotease inhibitors: design from structure. Biochem. Soc. Transactions 2004, 32, 17-20.

(C) 2010 by the authors; licensee MDPI, Basel, Switzerland. This article is an open access article distributed under the terms and conditions of the Creative Commons Attribution license (http://creativecommons.org/licenses/by/3.0/). 